\title{
Intertrial stimuli and differentiation of the conditioned eyelid response'
}

JOHN W. MOORE AND FREDERICK L. NEWMAN

UNIVERSITY OF MASSACHUSETTS

\begin{abstract}
Abstraet
One hundred thirty-six human Ss participated in two differential eyelid conditioning experiments designed to demonstrate the inhibitory properties of intertrial stimuli. In Experiment I when the intertrial stimulus was a tone (IT) lying midway between CS+ and CS- on the auditory frequency dimension differentiation was enhanced compared with a group which received only noise during the ITI, but this enhancement occurred only when CS+ and CS- were highly similar tones. In Experiment II differentiation was poorer where the order of stimuli along the frequency dimension was IT, CS+, CS- compared with IT, CS-, CS+。

Problem
\end{abstract}

The Perkins-Logan hypothesis assumes that simple conditioning is a special case of differential conditioning in which the CS is an S+ and the intertrial stimulus an S-. According to this view, the extent to which inhibition associated with the intertrial stimulus influences on-trial responding depends upon the amount of similarity between the intertrial stimulus and CSs. Moore \& Newman (in press) reported a series of experiments in which an eyelid CR was established to a pure tone CS+ and in which other pure tones (CS-'s) of equal intensity and duration as $\mathrm{CS}_{+}$, but differing in frequency, were interspersed among conditioning trials. The percentage of CRs to CS+ and to the CS-'s were plotted in the form of stimulus generalization gradients with the position of each tone on the frequency dimension indicated on the abscissa. The question was, what would happen to such generalization gradients if for the entire interval between CS presentations a tone of yet another-frequency was presented to the S? It was found that increasing the proximity of the intertrial stimulus to the CSs in this way produced a positive induction effect (Kimble, 1961, pp. 93-95) whereby the generalization gradients were sharpened by an increase in responding to $\mathrm{CS}+$ and decreases in responding to CS-'s, particularly those most similar to the intertrial stimulus. In all cases normally symmetrical gradients were sharpened and skewed away from the intertrial tone, and in some cases peak-shifting actually occurred. It appeared that inhibition accrued to the intertrial stimulus and that generalization of this inhibition affected responding to the CSs in much the same way that a proximal $\mathrm{S}^{\Delta}$ produces positive induction effects in instrumental conditioning (e.g., Hanson, 1959; Reynolds, 1961; Thomas \& Williams, 1963).

These considerations lead to the prediction that in differential conditioning an intertrial tone (IT) with a frequency lying midway between those of CS+and CSshould enhance differentiation compared with groups which receive only white noise during the intertrial interval. Furthermore, this enhancement should be greater where CS+ and CS- are close together than where they are well separated from each other and from the IT. Still another implication of our previous findings is that differentiation should be depressed when the IT is placed near CS+ compared with placement of the IT near CS-. These predictions were tested in the two experiments reported here.

\section{Method}

Subjects and Apparatus. The Ss were 177 undergraduates recruited from introductory psychology classes at the University of Massachusetts. Following Moore \& Newman (in press), some of the Ss were discarded from the data as high level responders $(\mathrm{N}=10)$, low level responders $(\mathrm{N}=22)$, and as having unreadable intertrial records $(\mathrm{N}=9)$. The apparatus, stimulus parameters, and general procedure were the same as in the earlier study.

Experiment I. Eighty Ss received $50 \mathrm{CS}+$ and $50 \mathrm{CS}-$ trials, randomly ordered. For half of the Ss (Condition $\Delta f=200) \mathrm{CS}+$ and CS- were pure tones $200 \mathrm{cps}$ apart on the frequency dimension (700 vs. $900 \mathrm{cps}$ or vice versa). For the other half (Condition $\Delta f=100$ ) the frequency separation was $100 \mathrm{cps}$ (700 vs. 800 or vice versa). Half of the $\mathrm{Ss}$ in each of these conditions received an IT $(800 \mathrm{cps}$ for $\Delta \mathrm{f}=200$ and $750 \mathrm{cps}$ for $\Delta f=100)$, and the other half received no IT but only white noise of $75 \mathrm{db}$ SPL during the ITI. The intensity of all tones in both experiments was also $75 \mathrm{db}$ SPL. Ten males and 10 females were run in each of the four main groups of Experiment $I$.

Experiment II. Fifty-six Ss received 70 differentiation trials (35 CS+ and $35 \mathrm{CS}-$ ) and 30 extinction trials (15 CS+ and $15 \mathrm{CS}-$ ). There were two main conditions. The ordinal position of the three tones along the frequency dimension was either IT, CS+, and CS- or IT, CS-, and CS+. The actual tones employed in the first condition were either IT $=600, \mathrm{CS}+=700$, and CS- $=900 \mathrm{cps}$; or, as a control for "direction, "IT $=900$, $\mathrm{CS}_{+}=800$, and $\mathrm{CS}-=600 \mathrm{cps}$. Under the second condition the tones were either IT $=600, \mathrm{CS}-=700$, and $\mathrm{CS}_{+}=900$ or $\mathrm{IT}=900$, CS $-=800$, and $\mathrm{CS}+=600$.

\section{Results and Diseussion}

Experiment I. Table 1 shows the mean percentage of $\mathrm{CRs}$ to CS+ and CS- for the four major conditions of Experiment I. As predicted, and enhancement of dif- 
ferentiation with an IT occurred with $\Delta f=100$ but not with $\Delta \mathrm{f}=200$. However, this interaction effect was found to be not significant according to an analysis of variance of the arcsine transforms of percentage scores, $\mathrm{F}(1,64)=2.22, \mathrm{p}<.15$.

Experiment II. Figure 1 shows the differentiation and extinction curves for the two major conditions of Experiment II. The predicted attentuation of differentiation in the group for which the IT and CS- were separated by CS+ appeared by the third trial-block, attained statistical significance over trial-blocks 6 and $7, F(1,48)=5.71, p<.05$, and continued for the first block of extinction trials. Perhaps the most interesting implication of Fig. 1 is that this attenuation of differentiation was due not only to a reduction of responding to $\mathrm{CS}_{+}$, but to an increase in responding to CS- as well. This result indicates a shift in the focus of excitation away from the IT and is analogous to the peak-shifting reported in our earlier study.

Intertrial Responding. Mean intertrial blink rates, based on the $10 \mathrm{sec}$. preceding each CS presentation, were .303 and .238 blinks/sec. for the IT and No-IT conditions of Experiment I, respectively. In Experiment II, mean blink rates during differentiation were .271 and .197 in the groups in which the IT was relatively near to and far from CSt, respectively. While the direction of these differences in both experiments are what would be expected if excitation generalizes from CS+ to IT (so as to inflate intertrial responding), they failed to approach statistical significance.

The positive induction effects which an intertrial stimulus can produce when it is similar to the CSs have been further elaborated in the experiments reported here. If positive induction is, in fact, the mechanism underlying these phenomena then the source of induction producing inhibition must be specified. Nonreinforced intertrial responses remains a likely contender. Even though measured rates of intertrial responding have not always agreed with our expectations (Moore \& Newman, in press), some intertrial responding does occur and this may be sufficient to generate the inhibition necessary for positive induction. A recent experiment by Terrace (1964) reinforces the view

\section{TABLE I}

Percentage of CRs to CS + and CS - for Trials 51-100 of Experiment $I$.

\begin{tabular}{rllll} 
Condition & \multicolumn{2}{c}{$\Delta f=100$} & \multicolumn{2}{c}{$\Delta f=200$} \\
\hline ITS & \multicolumn{1}{c}{$\mathrm{S}+$} & $\mathrm{S}-$ & $\mathrm{S}+$ & $\mathrm{S}-$ \\
No ITS & 71.6 & 32.6 & 67.4 & 36.6 \\
& 66.8 & 43.8 & 69.2 & 31.2
\end{tabular}



Fig. 1. Percentage of CRs to CS- (upper curves) and Cs- (lower curves) as a function of trial-block for the two major groups of Experiment II.

that nonreinforced responding at least enhances the effect. In tests of wavelength generalization in the pigeon-operant situation, peak-shifting did not occur following discrimination learning without errors, however some sharpening of the gradients was observed. These considerations suggest the need for an experiment in which induction effects in differential eyelid conditioning are measured under conditions where intertrial responding is somehow directly manipulated in the experimental design.

\section{References}

Hanson, H. M. Effects of discrimination training on stimulus generalization. J. exp. Psychol., 1959, 58, 321-334.

Kimble, G. A. Hilgard and Marquis conditioning and learning. (2nd ed.) New York: Appleton-Century-Crofts, 1961.

Moore, J. W., \& Newman, F. L. Intertrial stimuli and generalization of the conditioned eyelid response. J. exp. Psychol., in press.

Reynolds, G. S. Contrast, generalization and the process of discrimination. J. exp. Anal. Behav., 1961, 4, 289-294.

Thomas, D. R., \& Williams, J. L. A further study of stimulus generalization following three-stimulus discrimination. $J$. exp. Anal. Behav., 1963, 6, 171-176.

Terrace, H. S. Wavelength generalization after discrimination learning with and without error. Science, 1964, 144, 78-80.

\section{Note}

1. This investigation was supported in part by Public Health Service Grant NIH-HD-00955-02. The authors wish to acknowledge the assistance of Jean Pezzoli, Ruth Pollack, and Sandra Teguis. 